\title{
Perceptions of Congolese urban men and women of healthy and desirable body sizes
}

\author{
Michelle Holdsworth ${ }^{1}$, Philippe Hovette ${ }^{2}$, Sabrina Eymard-Duvernay ${ }^{3}$ and Francis Delpeuch ${ }^{3}$ \\ ${ }^{1}$ Division of Nutritional Sciences, University of Nottingham, Nottingham, UK, ${ }^{2}$ Clinique Total E\&P Congo, \\ Pointe-Noire, Congo and ${ }^{3}$ Institut de Recherche pour le Développement-IRD, UR106 Nutrition Alimentation, Sociétés, \\ Montpellier, France
}

Perceptions of body size can influence whether obesity is seen as desirable and therefore whether a population is motivated to change. Previous studies in Africa have given contradictory findings about whether obesity is culturally desirable ${ }^{(1)}$. The present study examines the cultural ideals for body size held by urban Congolese men and women, by determining the body size that men and women associate with health, assessing whether these ideals vary for males and females and assessing how accurately men and women classify their weight status.

A cross-sectional study was conducted in 2006 with all employees of Total oil and gas company, Pointe-Noire, Congo using a structured interviewer-administered questionnaire. Height and weight were measured to calculate BMI. To estimate ideals for body size, employees associated thirty items relating to social status (six items), health (nine items) and individual attributes (fifteen items) with one of nine silhouettes ranging from underweight to obese ${ }^{(2)}$. A total of 392 men and seventy-two women participated in the study (which represents all Congolese male and female employees based at Pointe-Noire, Congo during the data collection period).

Approximately $60 \%$ of men and $>70 \%$ of women were overweight or obese (overweight $43.1 \%$ men and $40.3 \%$ women; obese $16.8 \%$ men and $31.9 \%$ women; Table 1). Obese silhouettes were seen in an entirely negative light for males and females; they were seen as greedy, having a large appetite and as unhealthy, as they were more likely to be associated with developing CHD, hypertension, gout, diabetes and cancer. There were some beneficial views of overweight, as male overweight silhouettes were seen in a positive light for six of thirty items. On the other hand, female overweight was less acceptable and was seen positively for only two of thirty items. The vast majority preferred normal weight, and there were no preferences for underweight. Men and women shared similar views of male bodysize norms. However, men appeared to have a more favourable view of larger body sizes for women than women themselves, who have a social norm that is more constraining, i.e. men appear to prefer women to be larger than women do themselves. Men were better informed and made closer estimations of their weight status than women (Table 2), as more obese men (93.9\%) realised that they were overweight, although only $3.1 \%$ realised they were actually obese; the discrepancy was more marked for obese women, as only $77.3 \%$ realised they were overweight (and none saw themselves as obese) and $22.7 \%$ actually classified their weight as normal. This lack of awareness has implications for public health nutrition interventions.

Table 1. Anthropometric and socio-demographic characteristics of the sample $(n 464)$

\begin{tabular}{lcc}
\hline & Men $\left(\begin{array}{l}n \text { 392) } \\
\%\end{array}\right.$ & $\begin{array}{c}\text { Women }(n \text { 72) } \\
\%\end{array}$ \\
\hline Age (years) & & \\
$\quad \leq 40$ & 30.1 & 31.9 \\
$40-50$ & 41.3 & 37.5 \\
$>50$ & 28.6 & 30.6 \\
Educational level & & \\
$\quad$ GCSE equivalent & 20.0 & 29.0 \\
A level equivalent & 45.0 & 30.4 \\
Degree level & 35.0 & 40.6 \\
BMI group & & \\
$\quad$ Normal & 40.1 & 27.8 \\
Overweight & 43.1 & 40.3 \\
$\quad$ Obese & 16.8 & 31.9 \\
Mean BMI $\left(\mathrm{kg} / \mathrm{m}^{2}\right):$ & 26.4 (SD 4.3) & 28.1 (SD 4.9) \\
Waist:hip ratio $(n$ 520) & $0.90($ SD 0.07) & 0.84 (SD 0.07) \\
\hline
\end{tabular}

Table 2. Perceived weight classification from silhouettes $v$. actual BMI ( $\%$ total)

\begin{tabular}{lccccc}
\hline \multirow{2}{*}{$\begin{array}{l}\text { Perceived weight } \\
\text { classification }\end{array}$} & \multicolumn{5}{c}{ Actual BMI $\left(\mathrm{kg} / \mathrm{m}^{2}\right)$} \\
\cline { 2 - 6 } Men $(n$ 390) & $<18.5$ & $18.5-24.9$ & $25.0-29.9$ & $\geq 30$ & $P$ \\
$\quad$ Underweight & 0 & 10.4 & 0.6 & 0 & $<0.0001$ \\
$\quad$ Normal & 66.7 & 70.1 & 37.1 & 3.0 & \\
Overweight & 33.3 & 18.8 & 61.7 & 93.9 & \\
Obese & 0 & 0.7 & 0.6 & 3.1 & \\
Women $(n$ 68) & & & & & 0.0037 \\
$\quad$ Underweight & 0 & 11.1 & 3.7 & 0 & \\
$\quad$ Normal & 100 & 77.8 & 48.2 & 22.7 & \\
$\quad$ Overweight & 0 & 11.1 & 48.1 & 77.3 & \\
$\quad$ Obese & 0 & 0 & 0 & 0 & \\
\hline
\end{tabular}

The finding that normal-weight body sizes were seen in the most positive light by Congolese men and women in this workplace suggests that body size ideals will not be an obstacle for strategies focusing on weight reduction. However, raising awareness about the 'optimistic bias' respondents have to their own weight is needed to help motivate change. These attitudes may not be representative of those held by adults throughout Congo, as the socio-economic level of the employees in the study is higher than that of the general Congolese population.

1. Holdsworth M, Gartner A, Landais E, Maire B \& Delpeuch F (2004) Int J Obes (Lond) 28, 1561-1568.

2. Becker DM, Yanek LR, Matson Koffman D \& Bronner YC (1999) Ethn Dis 9, 377-386. 